\title{
Identidades Homossexuais na Territorialidade Tradicionalista
}

\author{
Homosexual Identities in Territoriality Tradicionalista \\ Las Identidades Homosexuales en la Tradicionalista Territorialidad
}

\author{
Edipo Djavan dos Reis Göergen ${ }^{1}$; Flavia Rubiane Durgante ${ }^{2}$.
}

1edipodjavan@yahoo.com.br, Universidade Federal de Santa Maria; ${ }^{2}$ flaviadur@gmail.com, Universidade Federal de Santa Maria

\begin{abstract}
Resumo
Este artigo apresenta o debate teórico que sustenta a pesquisa de mestrado desenvolvida pelo autor. Tendo por base suas vivências em contextos de tradicionalismo gaúcho, o autor deste trabalho tem percebido a grande quantidade de homossexuais, ou indivíduos que se auto-denominam não-heterossexuais, integrando as atividades artísticas do Movimento Tradicionalista Gaúcho, ou a territorialidade tradicionalista. Interessado em investigar tal fenômeno, o autor tem desenvolvido o projeto de pesquisa "Os Espaços Paradoxais de Relações Homoeróticas na Territorialidade Tradicionalista", sob orientação do prof. Dr. Benhur Pinós da Costa, no Programa de Pós-Graduação em Geografia (UFSM). Para que essa pesquisa seja realizada, levam-se em conta as relações de gênero e de sexualidade que estão envolvidas no tema. Dessa forma, por ainda se tratarem de temáticas tidas como insignificantes na sociedade em geral e marginalizadas no campo científico, para que o presente trabalho fosse empreendido, buscou-se amparo teórico nas geografias feministas e queer, segmentos contemporâneos da ciência geográfica.
\end{abstract}

Palavras-Chave: Geografia, Gênero, Sexualidade, Território, Territorialidade.

\begin{abstract}
This paper presents the theoretical debate that sustains the master's research developed by the author. Based on his experiences in gaucho traditionalism contexts, the author of this work has seen a lot of homosexuals, or individuals who call themselves non-heterosexual, integrating the artistic activities of the Movimento Tradicionalista Gaúcho, or traditionalist territoriality. Interested in investigating this phenomenon, the author has developed the research project "The Paradoxical Spaces of Homoerotic Relationships in Territoriality Traditionalist", under the guidance of prof. Dr. Benhur Pinós da Costa, in the Graduate Program in Geography (UFSM). For this research is carried out, it is considered gender relations and sexuality that are involved in the issue. Thus, for still they refer to issues regarded as insignificant in the larger society and marginalized in the scientific field, for which this work was undertaken, we sought theoretical support in feminist and queer geographies, segments of contemporary geographical science.
\end{abstract}

Keywords: Geography, Gender, Sexuality, Territory, Territeriolity.

\section{Resumen}

Este artículo presenta el debate teórico que sostiene la investigación de máster desarrollada por el autor. Teniendo por base sus vivencias en contextos del tradicionalismo gaúcho, el autor de este trabajo ha percibido la gran cantidad de homosexuales, o individuos que si auto-denominan no-heterossexuais, integrando las actividades artísticas del Movimiento Tradicionalista Gaúcho, o la territorialidade tradicionalista. Interesado en investigar tal fenómeno, el autor ha desarrollado el proyecto de investigación "Los Espacios Paradoxais de Relaciones Homoeróticas en la Territorialidade Tradicionalista”, bajo orientación del prof. Dr. Benhur Pinós de la Costa, en el Programa de Postgrado en Geografía (UFSM). Para que esa investigación sea realizada, se llevan en cuenta las relaciones de género y de sexualidade que están envueltas en el tema. De esa forma, por todavia tratarse de temáticas tenidas como insignificantes en la sociedad en general y marginalizadas en el campo científico, para que el presente trabajo fuera emprendido, se buscó el apoyo teórico en las geografías feministas y queer, segmentos contemporáneos de la ciencia geográfica. 
Palabras claves: Geografía, Género, Sexualidad, Territorio, Territorialidad.

\title{
1. Introdução
}

A Geografia desde sua gênese convive com conflitos teóricos, epistemológicos e metodológicos que abarcam grande parte da sua estruturação enquanto ciência. A ciência, historicamente, intensificou seus estudos de acordo com os fenômenos que mais chamavam a atenção acadêmica em cada período. Gomes, analisando o processo de transformação epistemológica da Geografia afirma:

\begin{abstract}
A principal vocação da epistemologia é pois, desde o início, constituir um campo de discussão, de questões sobre métodos e limites de validade, sua inclinação não é normalizar nem restringir as iniciativas. Podemos, de forma muito geral, dizer assim que a epistemologia é um campo crítico de discussões sobre as formas de pensamento científico. Isto quer dizer que essas discussões epistemológicas dizem respeito antes de mais nada aos métodos, aos objetivos e as finalidades de um conhecimento científico [grifo nosso] (GOMES, 2009, p. 14-15).
\end{abstract}

Para tanto:

Discutir criticamente as formas de construir um pensamento científico não quer absolutamente dizer se transformar em um tribunal para julgar da sua conformidade ou não em relação a um modelo único e ideal, ao contrário (GOMES, 2009, p. 1415).

A ciência, em concordância com a sociedade, ainda é fortemente alicerçada em ideais tradicionais e conservadores. Os geógrafos, em sua grande maioria, tendem a compreender as relações homem-natureza através de suas concepções mais tradicionais, sendo as novas temáticas marginalizadas no campo científico. Quem nos permite pensar desta maneira, por exemplo, é Cesar e Pinto (2015, p. 121), que através de uma classificação de artigos por palavras-chave concluram que, de um total de 13.999 trabalhos acadêmicos apenas 167 destes, ou seja, 1,2\% destes tratavam de questões de gênero, e 49, equivalentes a 0,3\%, equivalentes a temática das sexualidades.

A geografia na contemporaneidade, por exemplo, é muito mais que uma desenfreada busca pela descrição do espaço, ou até mesmo uma crente adoção às concepções metodológicas de interpretação espacial (SPOSITO, 2001, p. 101). Ela ultrapassou os antigos paradigmas, vindo ao encontro das novas interpretações de realidade, da mesma forma que traz ao meio acadêmico indivíduos historicamente invisibilizados, tanto pela sociedade quanto pelo meio científico. De acordo com Silva:

As ausências e os silêncios de determinados grupos sociais são resultantes de embates desenvolvidos na comunidade científica, que criam hierarquias e dependências, ratificando o poder de grupos hegemônicos e, consequentemente, de suas próprias teorias científicas $(2009$, p. 25). 
Complementando:

A ciência geográfica hegemônica é marcada por privilégios de sexo e de raça, características que dificultam a expressão das espacialidades dos grupos das mulheres, dos não-brancos e dos que não se encaixam na ordem heterossexual dominante (...) Durante muito tempo, as existências espaciais desses grupos ou de suas ações concretas não foram consideradas "adequadas" como objetos de estudos do campo da geografia. (...) A razão de suas ausências no discurso geográfico deve ser entendida pela legitimação naturalizada dos discursos hegemônicos da geografia branca, masculina e heterossexual, que nega essas existências e também impede o questionamento da diversidade de saberes que compõem as sociedades e suas mais variadas espacialidade (SILVA, 2009, p. 25).

Para tanto, as temáticas relacionadas ao gênero e sexualidade tem sido com certa relutância, objeto de interesse da geografia em diferentes esferas e em todos os cantos do globo. No Brasil ela ainda é incipiente e conta com poucos trabalhos relacionados a esta temática. Ainda é um campo dentro da ciência geográfica a ser explorado, e que oferece uma gama de interpretações com relação ao espaço. Ainda que haja inúmeras possibilidades de se verificar e analisar a diversidade no que se refere ao gênero e suas espacialidades, a geografia pouco se utiliza desta temática para compreender o espaço sob a perspectiva de relações sociais, justificando a importância de discussões acerca desse campo na ciência geográfica.

\section{Gênero e Sexualidade na Análise Geográfica}

As Geografias Feministas e Queer surgem da necessidade de integrar à Geografia inovações e diferentes problematizações que são vividas no cotidiano, ou em espacialidades marginalizadas pela ciência, e que exigem novas perspectivas de interpretação. Silva nos ajuda a compreender:

É importante esclarecer que entendo a Geografia como uma ciência social cujo objeto é o espaço geográfico, portanto acredito que não existam diferentes geografias - Geografia física, econômica, da população, de gênero. Mas considero que o conhecimento da totalidade deste espaço geográfico passa pela apreensão de uma realidade que se modifica constantemente e para conhecê-la precisamos fazer recortes (1998, p. 105).

De acordo com Silva, esse novo ramo de estudos da ciência geográfica é fruto dos movimentos sociais, principalmente o feminista:

Dentre os vários movimentos sociais emergentes nos anos 60, o movimento feminista, notadamente aquele reconhecido como a "segunda onda", foi fundamental para a inspiração da ação de geógrafas que iniciaram um movimento interno à geografia nos anos 70, sob a perspectiva de três objetivos principais: [1] construir a igualdade entre homens e mulheres no âmbito da disciplina; [2] centrar as investigações geográficas sobre as mulheres; e [3] desafiar as filosofias, conceitos e metodologias que sustentavam a hegemonia da geografia masculina (SILVA, 2009, p. 27). 
Dessa forma:

Assim como as mulheres brancas reivindicavam, na década de 70, espaços teóricos e políticos de hegemonia masculina, as mulheres negras oriundas de países em desenvolvimentos reivindicavam, agora, o reconhecimento de suas experiências específicas nem contexto de globalização que deveria contemplar a multiplicidade étnica, racial e sexual (SILVA, 2009, p. 39).

Considerar a pluralidade da sociedade requer uma atenção especial, pois se sabe que alguns padrões sociais ainda são conservadores. De uma forma semelhante Gomes afirma:

De forma global, podemos dizer que a partir dos anos 50 uma grande parte dos geógrafos passa a reconhecer a insuficiência e fraqueza das bases teóricas que pretendiam sustentar o projeto científico da geografia naquele momento. Essa insuficiência provinha em grande parte da resistente ideia de que a ciência geográfica se identificava inteiramente com o conhecimento empírico dos lugares e não precisava necessariamente ultrapassar esse estágio, ou seja, não precisava criar teorias ou explicações abstratas gerais. Ela seria, portanto, uma ciência diferente das demais pois, não só privilegiava o conhecimento concreto como se limitava a ele (GOMES, 2009, p. 17).

Neste sentido, basta falar em gênero (a priori, feminino e masculino) que se iniciam as discussões e principais problemas referentes as padronizações sociais. Para tanto, a pesquisa sobre as Geografias Feministas e Queer, são estudos emergentes no âmbito da ciência geográfica, uma vez que os fenômenos estão surgindo em proporções notáveis e estão intimamente ligados a atual configuração do espaço. Silva salienta que a Geografia Feminista não se limita a um mero estudo das mulheres no espaço, ela vai além.

Considero que a Geografia dita feminista é aquela que incorpora as contribuições teóricas do feminismo à explicação e interpretação dos fatos geográficos e o gênero é um dos resultados dessas contribuições, ou seja, uma categoria útil de análise geográfica. [...]Trata-se, então, de explicitar as desigualdades. A Geografia, de uma maneira geral, tem considerado a sociedade como um conjunto neutro, assexuado e homogêneo. [...] [Logo], Entendido que o espaço não é neutro do ponto de vista do gênero, torna-se necessário incorporar as diferenças sociais entre mulheres e homens e as diferenças territoriais nas relações de gênero (1998, p. 108).

De acordo com Silva:

A adoção do conceito de gênero pelas geógrafas feministas permitiu avanços teóricos e metodológicos, além da ampliação do campo de estudos, já que o espaço passou a ser um importante elemento para a compreensão das relações de gênero instituídas socialmente, contudo, hierarquizada, com primazia dos homens em relação às mulheres $(2009$, p. 35).

Da mesma forma, tratando da teoria queer:

A teoria queer, portanto, além de sua importância capital em reconhecer a formação de comunidades e culturas sexuais, é um espaço teórico no qual se pode evidenciar a exclusão e a marginalização de determinados grupos sociais nas atividades econômicas e políticas, frutos da homofobia. Segundo eles, mais do que leitura 
queer do espaço, é necessário empreender uma leitura queer da própria geografia, que tem banalizado esse campo de produção científica (SILVA, 2009, p. 44).

A potencialidade da teoria queer, vem da abordagem a qual leva à compreensão de culturas sexuais e a evidenciar a exclusão e a marginalização de determinados grupos sociais, resultado de práticas homofóbicas nas atividades econômicas e políticas. Neste sentido, a subversão pode desestruturar os espaços, ou seja, as práticas e também estudos subversivos podem ser fundamental para ressaltar esses grupos marginalizados. Conclui-se que gênero é uma construção cultural e social e, como tal, sua representação e disseminação pelos meios comunicacionais é responsável pela construção de ideais sociais, valores, estereótipos e preconceitos.

\section{Territorialidade Tradicionalista e Respectivos Territórios}

De acordo com Claval:

Os geógrafos dos anos sessenta atribuíam tudo ao espaço. Hoje em dia, eles falam mais comumente de território. Essa mudança reflete em parte os debates epistemológicos internos à geografia. Ela é, sobretudo, testemunha de uma profunda transformação do mundo, e de uma mutação correlata das maneiras de compreendêlo. [...] a partir de agora é aos lugares e àquilo que os diferenciam que muitos se referem para dizer o que eles [os territórios] são e em que se distinguem uns dos outros $(1999$, p. 7).

Assim sendo, esse trabalho, proveniente das leituras direcionadas ao texto de dissertação do autor, fortemente embasado pelas concepções teóricas e epistemológicas das Geografias Feministas e Queer, objetiva compreender a construção de identidades homoeróticas na territorialidade tradicionalista, a espacialidade que agrega o Movimento Tradicionalista Gaúcho. Para tanto, compreende-se os centros de tradições gaúchas e demais eventos como os territórios a serem estudados, e o Movimento Tradicionalista Gaúcho uma territorialidade.

Inicialmente, buscamos em Sack (1986) referencial para compreendermos o que seria territorialidade. Esta, para o referido autor, pode ser entendida como territorialidade humana, como uma forma espacial de comportamento social. A territorialidade está intimamente relacionada à utilização da "terra" por um determinado grupo, ela está diretamente relacionada à organização de um dado no espaço tempo. Portanto, a territorialidade é um componente geográfico central para entender como a sociedade e o espaço estão intimamente relacionados.

Contextualizando-se ao Movimento Tradicionalista Gaúcho, este, com o passar dos anos, conseguiu ultrapassar as "paredes" delimitatórias do 35 CTG (primeiro Centro de 
Tradições Gaúchas, criado em 1947), e de seus demais Centros de Tradições Gaúchas, manifestando-se nos mais variados âmbitos sociais. Conforme Brum, o movimento se expande por todo o Brasil e mundo "sendo lá cultuado por gaúchos, descendentes e também por simpatizantes" (2006, p. 3). Eventos, programas de rádio, televisão, jornais, sites e livros carregam consigo a "marca" do tradicionalismo e, sem contar os mais de 2.700 núcleos de difusão e culto ao tradicionalismo cadastrados, de acordo com o site da Confederação Brasileira de Tradição Gaúcha.

Sack (1986) ainda complementa argumentando que, como intenção de indivíduos ou grupos de produzir, influenciar ou controlar pessoas, fenômenos e relações, isto se dá através da delimitação e defesa de uma determinada área geográfica. Essa área, então, pode ser entendida como um território.

O MTG tem sua gênese em 1954, e com o passar dos anos, novos Centros de Tradições Gaúchas, ou demais núcleos difusores, se formaram na espacialidade gaúcha. Ou seja, o MTG não se enquadra mais em um único ponto de difusão de ideias, como, inicialmente se deu, com a fundação do 35 CTG. Com o passar do tempo, novos núcleos foram se formando, "produzindo, influenciando ou controlando" indivíduos, e então, melhor fortalecendo e alicerçando suas normas sociais, de grupo, de conduta, identitárias.

Somente no Rio Grande do Sul estão em prática 30 Regiões Tradicionalistas, agregando a todos os municípios do estado. Cada uma dessas, assim como o próprio MTG, existe uma estrutura de poder rigidamente obedecida. Da mesma forma, cada entidade tradicionalista tem sua estrutura erguida obedecendo à determinadas regras estruturais. Há controle físico e comportamental. De uma forma muito reduzida, o próprio Movimento disponibiliza sua estruturação em seu site:

O MTG é administrado por um Conselho Diretor composto de trinta e três (33) membros efetivos e dezesseis, chamados Conselheiros, eleitos em Assembleia Geral eletiva realizada anualmente no Congresso Tradicionalista. O mandado do Conselheiro efetivo é de dois anos, os quais escolherão, dentre si, um Presidente, um Vice-Presidente de Administração e Finanças, um Vice-Presidente de Cultura, um Vice- Presidente Campeiro, um Vice- Presidente Artístico e um Vice- Presidente de Esportes Campeiros, estes com mandato de um ano. Juntamente com os titulares, são eleitos dezesseis (16) suplentes, com um mandato de um (1) ano (MTG).

Dessa maneira, percebe-se a construção de uma estrutura de poder, que Raffestin (1993) e Souza (1995) podem nos assegurar, enquanto se encara os Centros de Tradições Gaúchas, assim como as demais festas e eventos proporcionados pelo MTG, como territórios. Porém, vale-se lembrar que Souza (p. 87) acrescenta a Identidade como termo ilustrador de 
uma configuração territorial. Quem nos auxilia a engrossar essa possibilidade teórica é Saquet, o qual afirma que:

As identidades são produzidas historicamente por relações identitárias, coletivas, grupais [...] Há uma construção do território que produz identidade e, no nosso entendimento, uma construção de identidade que produz o território; este processo é produto de ações coletivas, recíprocas, de atores sociais (2005, p. 13872).

De forma semelhante, Ritter afirma que:

[...] 'poder' e 'identidade' não se opõem, pelo contrário tendem a se complementar e a se integrar, uma vez que toda identidade é socioculturalmente construída e permanentemente reconstruída pelos contextos, nas mais diversas escalas, a partir de valores herdados e da ação das forças hegemônicas, cujo objetivo principal é aglutinar, mobilizar, criar sinergias para a aceitação e para a legitimação das imposições coletivas e demais faces do poder (2011, p. 99).

Complementando, unindo território à identidade, Claval argumenta dizendo que "o sentimento identitário permite que se sinta plenamente membro de um grupo, dotá-lo de uma base espacial ancorada na realidade" (1999, p. 16). Para tanto, "a construção das representações que fazem certas porções do espaço humanizado dos territórios é inseparável da construção das identidades" (1999, p. 16).

No meio tradicionalista é possível se perceber a crença de partilha de um senso identitário único. Para os tradicionalistas, crer na possibilidade de que os gaúchos são "filhos" de um povo autóctone do solo sul-riograndense é uma lei. Não seria tamanho equivoco se se levasse em conta a já citada colonização heterogênea, porém, se é pelo fato de que o povo autóctone, para os seguidores do MTG, ser um possível grupo portador de bombachas, a muitos séculos. O Movimento Tradicionalista Gaúcho criou, e persistem em reafirmar, um personagem mítico para o Rio Grande do Sul. Conforme comenta Golin,

No estágio atual da cultura rio-grandense, encontram-se elementos cujos valores sociais foram esterilizados pelo gauchismo. Foi preciso desarmar toda a historia real e construir uma outra história, que, antes de ser entendida como manipulação, deve ser compreendida como a criação de um complexo arcabouço cultural que colocou a história humana em uma inversão. (GOLIN, 1983, p. 23).

Logo, ao se pensar no "gaúcho", remete-se não mais ao habitante do Rio Grande do Sul mas sim, a um ser quase mitológico e apenas presente na literatura e nas práticas do Movimento tradicionalista Gaúcho. Este porta bota e bombachas, e suas "companheiras" um vestido colorido, e falam, se comportam e manifestam-se como se estivessem num tempo passado historicamente inexistente. É como que ao adentrar os "limites" da territorialidade tradicionalistas, os indivíduos fossem "possuídos” por específicas atitudes e modos de agir. 
Levando-se em conta as pós-modernas concepções de identidade de Stuart Hall, notase que não se tem uma identidade fixa, essencial ou permanente, ela se tornou uma "celebração móvel: formada e transformada continuamente em relação às formas pelas quais somos representados ou interpelados nos sistemas culturais que nos rodeiam”. Ainda para o autor,

O sujeito assume identidades diferentes em diferentes momentos, identidades que não são unificadas ao redor de um "eu" coerente. Dentro de nós há identidades contraditórias, empurrando em diferentes direções, de tal modo que nossas identificações estão sendo continuamente deslocadas. [...] A identidade plenamente unificada, completa, segura e coerente é uma fantasia. Ao invés disso, à medida em que os sistemas de significação e representação cultural se multiplicam, somos confrontados por uma multiplicidade desconcertante e cambiante de identidades possíveis, com cada uma das quais poderíamos nos identificar - ao menos temporariamente [grifo nosso] (HALL, 2005, p. 12-13).

Assim sendo, se percebe que cada indivíduo pode "possuir" várias identidades, variando ela de acordo com a situação vivenciada, o espaço visitado, ou então, a territorialidade em que faz parte. Em tempo, adere-se a ideia de performatividade, que Butler utiliza para caracterizar das identidades de gênero. De acordo com a autora,

[...] atos, gestos e desejo produzem o efeito de um núcleo ou substância interna, mas o produzem na superfície do corpo, por meio do jogo de ausências significantes, que sugerem, mas nunca revelam, o princípio organizador da identidade como causa. Esses atos, gestos e atuações, entendidos em termos gerais, são performáticos, no sentido de que a essência ou identidade que por outro lado pretendem expressar são fabricações manufaturadas e sustentadas por signos corpóreos e outros meios discursivos (BUTLER, 2008, p. 194).

Logo, notando a tamanha afinidade, ou consequência, entre identidade e performance, pode-se concluir que, para cada territorialidade existe uma performance em específico. Ao "adentrar" a espacialidade tradicionalista a adesão do indivíduos de um modo de agir característico. Logo, porque não se dizer de performático, ou então, uma performance tradicionalista. Esse modo de ser e se portar refletem um comportamento fortemente conservador, machista, elitista e heteronormativo. Levando em conta que cada território não é composto homogeneamente, e sim, também por disputas internas de poder, permitindo notar assim porções espaciais centrais e marginais (ROSE, 1993), nota-se também que esta performance não é hegemônica. Da mesma forma, através dos escritos de Hall (2005), vem-se a crer que todos os indivíduos componentes dessa territorialidade possuem outras tantas identidades, e consequentes performances, manifestas em demais espaços-tempos.

Percebendo a grande quantidade de homossexuais, ou então, indivíduos que se autodenominam não-heterossexuais, habitando a territorialidade do MTG, e que sua sexualidade não se encaixa no propagado pela referida entidade, vem-se questionar, de que maneira tais 
indivíduos convivem nesses espaços tendo suas identidades (HALL, 2005) em constante conflito. (ORNAT, 2009, p. 203-204).

\section{Considerações Finais}

Ao se pesquisar sobre a evolução histórica da sociedade, e o consequente despontar de novas identidades, performances e grupos de indivíduos, nota-se o lento, mas gradual, amadurecimento e aperfeiçoamento do campo científico para com tais "novidades". Dentro de cada disciplina científica, não é diferente, vindo a surgir novas correntes de interpretação de realidade, com o transcorrer dos tempos.

Seguindo-se a mesma lógica, nota-se que, no caso da geografia, as suas diferentes categorias de análise também mutaram e se aperfeiçoaram com o percorrer da sociedade. no caso do território, como se foi possível perceber no texto, passou por graduais aperfeiçoamentos interpretativos, à medida que novos agrupamentos humanos foram surgindo, e novas concepções de realidade se desenvolvendo.

Do equivalente à nação, com Ratzel (1983); a grupos regidos por relações de poder, de Raffestin (1993); à espacialidades portadoras de um agrupamento étnico, de Bonnemaizon (2002); a coletivos que partilham de uma mesma identidade, de Saquet (2005); e porque não, aderindo-se à novas correntes de pensamento social de Butler (2003), considerar um território um agrupamento de indivíduos que se manifestam com uma performatividade semelhante.

Nesse sentido, Claval argumenta,

O interesse que suscita a noção de território, e as novas formas de territorialidade e as geopolíticas que elas implicam é considerável. É explorando essas modalidades inéditas de relações dos grupos com o espaço que os geógrafos podem trabalhar positivamente por um mundo melhor e mais justo (CLAVAL, 1999, p. 24).

Portanto, conclui-se que, para melhor se compreender a(s) realidade(s) de uma forma científica, deve-se levar em conta a sua constante mutação, indo ao encontro de novas possibilidades teóricas e metodológicas, desde que as comumente usadas encontram-se saturadas ou improdutivas. Ao se estudar os grupos de indivíduos historicamente, socialmente e espacialmente marginalizados, deve-se buscar amparo nos segmentos teóricos que os perceba e os valide.

\section{Referências}

BONNEMAISON, J.; VANUATU. O. Viagem em torno do território. In: CORRÊA, R. L.; ROSENDAAL, Z. (Org). Geografia Cultural: um século. Rio de Janeiro: EDUERJ, 2002. 
BUTLER, J. Problemas de Gênero: Feminismo e subversão da identidade. Rio de Janeiro: Civilização Brasileira, 2003.

BRUM, C. K. "As (re) configurações do gauchismo" pensando as relações entre o movimento tradicionalista gaúcho e a escola. In, Disponível em < http://coral.ufsm.br/gpforma/2senafe/PDF/019e3.pdf $>$. Acesso em 24 de junho de 2015.

CESAR, T. R. A. O.; PINTO, V. A. M. A Produção Intelectual da Geografia Brasileira, entorno das Temáticas de Gênero e Sexualidades: uma visão a partir dos periódicos on line. In, Revista Latino-americana de Geografia e Gênero, Ponta Grossa, v. 6, n. 2, ago. / dez. 2015, p. 119-132.

CLAVAL, P. O território na transição da pós-modernidade. In, GEOgraphia, ano 1, n 2, 1999, p. 7-26.

CONFEDERAÇÃO BRASILEIRA DE TRADIÇÃO GAÚCHA. Disponível em <http://www.cbtg.com.br/_sitio/ctgs/mapa.php〉. Acesso em 14 de outubro de 2014.

GOMES, P. C. Um lugar para a Geografia: contra o simples, o banal e o doutrinário. In, MENDONÇA, F. A., LOWEN-SAHR, C. L., SILVA, M. (org.). Espaço e tempo: complexidade e desafios do pensar e do fazer geográfico. Curitiba: Associação de Defesa do Meio Ambiente e Desenvolvimento de Antonina (ADEMADAN), 2009, p. 13-30.

GOLIN, T. A ideologia do gauchismo. Porto Alegre: Tchê, 1983.

HALL, S. A identidade cultural da pós-modernidade. 10ª ed. Rio de Janeiro: DP\&A, 2005.

MTG, site. Disponível em 〈www.mtg.org.br . Acesso em 24 de junho de 2015, às 18:50 horas.

ORNAT, Marcio Jose. Espacialidades travestis e a instituição do território paradoxal. In, SILVA, Joseli Maria (org.). Geografias Subversivas: discursos sobre espaço, gênero e sexualidades. Ponta Grossa: Todapalavra, 2009, p. 177-210.

RAFFESTIN, C. Por uma Geografia do Poder. São Paulo: Ática. 1993.

RATZEL, F. O solo, a sociedade e o estado. In, Revista do Departamento de Geografia USP, v. 2 , 1983, p- $93-101$.

RITTER, C. Reflexões epistemológicas sobre os "territórios de identidade". In, Revista Geografar, Curitiba, v. 6, n. 1, jun. 2011, p. 95-109.

ROSE, G. Feminism \& Geography: the limits of geographical knowledge. Cambridge: Polity Press, 1993.

SACK, R. D. Human Territorility - Its Theory and History. Cambridge: Cambridge University Press, 1986.

SAQUET, M. A. Território e identidade. In, Anais do X encontro de geógrafos da América Latina, Universidade de São Paulo, São Paulo, mar. 2005, p. 13869-13881. 
SILVA, J. M. Fazendo geografias: pluriversalidades sobre gênero e sexualidade. In: SILVA, Joseli Maria (org.). Geografias Subversivas: discursos sobre espaço, gênero e sexualidades. Ponta Grossa: Todapalavra, 2009, p. 25-54.

SILVA, S. M. V. Geografia e gênero/geografia feminista: o que é isto? In, Boletim Gaúcho de Geografia, no 23, Porto Alegre: UFRGS, 1998, p. 105-110.

SOUZA, M. L. O território: sobre espaço e poder, autonomia e desenvolvimento. In: CASTRO, Iná et. al. (Orgs.). Geografia: Conceitos e Temas. Rio de Janeiro: Bertrand Brasil, 1995. p.77-116.

SPOSITO, E. S. A propósito dos paradigmas de orientações teórico-metodológicas na Geografia contemporânea. In, Terra Livre, São Paulo, n. 16, 2001, p. 99-112. 